\title{
"Coming, ready or not!": What Counts as Early Literacy?
}

\section{Barbara Comber, $(1999$}

Coming ready or not!" Now there's a familiar refrain from our own early childhood days. It brings to mind long summers where children (in my family) were banished to "play outside" sometimes in bare shadeless backyards where hiding spots were at a premium. I begin with this refrain in order to invoke memories of childhood-the sounds of children, their agendas, their games — and to take me to the idea of "readiness" as it relates to schooling.

Historically, and I would argue today, "readiness" functions as a key symbol in discourses of early childhood. The extent to which children are ready for school, ready to read implies a major contradiction with education. On the one hand, schools are readiness/training/preparation institutions par excellence-"nurseries of the population"1 wherein children are made into students and would-be citizens. On the other hand, paradoxically, there is a sense in which children must be made ready for their institutional life, presumably by their families, with the preschool (or kindergarten) functioning as a transitional institution. Much research and scholarship over this century has gone into producing developmental grids by which children's readiness, across social, physical, psychological and educational criteria can be assessed. Indeed, increasingly there are international moves to produce baseline data on preschoolers' and school beginners' literacy and numeracy. The belief seems to be that the more we know (read "assess") the better the pedagogical match. However, an inevitable side-effect of the production of grids of so-called "normal" development is the eliciting of failure, deviance and abnormality—the always forever "unready."

In this paper, I argue that schools and teachers need to make "ready" for children and to make ready for different children in a very different world than that in which many of us grew up. My interest is not only in individual differences, but also in differences in the linguistic, social, economic and cultural capital ${ }^{2}$ that different children bring to school and what they do with what schools makes available. Bourdieu's analysis of the ways in which particular educational institutions work in relation to specific groups of people provides an illuminating theory for re-considering children's transitions to school, and their engagements (or not) with literacy curriculum in particular.

[B]y virtue of the habitus, individuals are already predisposed to act in certain ways, pursue certain goals, avow certain tastes, and so on. Since individuals are the products of particular histories which endure in the habitus, their actions can never be analysed adequately as the outcome of conscious calculation. Rather, practices should be seen as the product of an encounter between a habitus and a field which are, to varying degrees, 'compatible' or 'congruent' with one another, in such a way that, on occasions when there is a lack of congruence (e.g. a student from a working-class background who finds himself or herself in an elite educational establishment), an individual may not know how to act and may literally be lost for words. ${ }^{3}$ 
Thompson's summary of the habitus is useful in reading the contrastive classroom data which follows and begins to suggest how there is different work involved in beginning school and in being inculcated into school literacies for different children. What counts as capital-as valued social products—is contingent upon the structures and the structuring practices of schooling.

I am concerned here with what different children "bring to school" and also with what schools make available and how different children take up such opportunities. Through examining how children's knowledges and practices count in school life (or not), we can design workable responsive and inclusive curricula. Examination of the pedagogical practices of highly effective early childhood teachers has much to offer in reconceptualising and reinventing curriculum and pedagogies for new times.

Children's take up of preschool curricula and pedagogies is contingent upon their existing capital and habitus. This raises some important questions for early childhood teachers.

- What different opportunities for literacy learning are available to different children?

- How do children's participative repertoires (and preferred ways of interacting) make a difference to what they elicit, access and take up in school?

- How do the enactments of (gendered, racialized, classed, sexed) literate practices enable some children to "cash in" their knowledges and skills at school and others not?

- What kinds of child "cultural capital" and "habitus" count in different early childhood environments (yard, school, classroom)?

\section{Working with Children's Linguistic and Cultural Resources}

A most important and enduring puzzle for many early years teachers involves reconceptualizing social justice in education, particularly in these times when there are increasing gaps between the rich and the poor in post-industrialized nation states and increasing chances of long-term under-employment. The extent to which classroom practices are socially just is decided in a moment by moment fashion in everyday institutional practices. For these reasons I believe it is important to look at what goes on in different classrooms in situated literacy lessons. Here I consider the practices of a number of early childhood educators, who have in common a commitment to making their literacy classrooms sites of pleasure, power and learning, by making what counts congruent with the resources and practices children bring to school.

Starting from where children are at," using "what children bring," and "building on children's strengths" have been key slogans of early childhood education discourses, but what does this mean in socially diverse and poor school communities? What might count as powerful and pleasurable forms of literacy which take up what children bring and add to it in significant ways. Here I explore just three ways (and these are by no means discreet) in which teachers are working with these challenges. I consider the use of 
"everyday texts," "everyday problems" and "popular culture" as the objects of study and text production in early childhood classrooms.

\section{Everyday Texts}

Everyday texts may include the signs, packages, junk mail, fliers and so on that saturate the environment on screens, billboards, buses, in letterboxes, workplaces, shopping centres and homes. Early childhood teachers ha ve long been experts in using environmental print, old magazines and packages. However, what I'm advocating here is more than its use as productive recycling, role-play or craft material. Sue Mahony is an early childhood teacher in South Australia. Several years ago Sue began deconstructing the gendered nature of toy advertisements on television and in catalogues with her children. While not denying the obvious pleasure children got from toys nor their associated marketing, Mahony engaged the children in repeated readings and viewings of these texts in order to explore how these texts worked to construct the desires and limits of pleasure and activity for boys and girls. Sue has gone on to write about this work for other teachers and is producing an enlarged texts for other teachers to use ${ }^{4}$. In an early trial version of this text her invitations to children included the following:

Before you buy a toy, you could think about:

- How strong the toy is and therefore how long it is likely to last?

- Does the toy come with instructions or safety information?

- What sort of play does the toy encourage?

- What sort of space you need?

- What do you learn about being a boy/girl when playing with video games?

- How are most problems solved in video games?

- What words and pictures is the advertiser using to influence you to buy the product?

Choose wisely and have fun!

The critical potential of this work is clear, but here I want to make several additional observations. In making toys and their associated marketing the object of study, Mahony is working towards a goal that children learn to be critical consumers and that they question the limited identity formations presented. However she is also making important something the children know a lot about: toys, the desire for toys, the use of toys, gendered divisions of play. This is high status material amongst four- to eight- year-olds. Knowledge of (not to mention ownership of) "in" toys, their names and their features counts as significant cultural capital amongst children's peer groups. Rather than banning toys from the classroom or consigning their appearance to morning talks, by making toys 
and their marketing the object of study, they are valorized as significant and worthy of consideration. However it is important not to assume that Mahony's intent here is "corrective." While her questions make available to children what might be different ways of thinking about toys and their advertising, this is also pleasurable work.

In the context of "re-reading" the toy catalogues and advertisements, children have fun; a space becomes available in the official world of school for children to talk about their knowledge and experience. It is important to make this clear as often early childhood educators are rightly sceptical of "critical literacy" as forms of training in political correctness. While Mahony's questions do offer children new resources for considering their experiences they do not discount children's experience of pleasure.

Mahony's work is part of a growing corpus of classroom research in the early years in South Australia where educators have applied feminist theory or anti-sexist curriculum principles to the early childhood classroom. ${ }^{5}$ In the case of Mahony's work, the topic of the texts, toys, is clearly relevant to young children. However the scope for the use of such texts it seems is limited only by teachers' ${ }^{6}$ imaginations. Marg Wells and her colleagues studied the wrappings and instructions on Kinder Surprise Chocolates, and the information tags on trees and pla nts from nurseries; Jenny O'Brien investigated the junk mail advertising of cultural events, such as Mothers' and Father's Days; other teachers have explored the texts of food packaging such as cereal boxes, chip packets and so on ${ }^{7}$ Teachers have found that this material is highly interesting to young children-not surprising given that millions of dollars are spent on designing, constructing and distributing these everyday texts.

\section{Everyday Problems}

Another way of using children's resources and funds of knowledge is to engage them in dealing with everyday school and community problems. Vasquez is an early childhood teacher in suburban Toronto in a highly multi-cultural Catholic school. The objects of discussion, reading and writing in Vasquez' room were produced in the context of everyday school life. ${ }^{8}$ To illustrate, on one occasion an older class in the school had organized a restaurant for a day, a French Cafe. The problem was that the kindergarten classes were not invited. When this came to the attention of the children, they became very upset about being excluded in this way and Vasquez asked them what they could do about it.

They discussed options - complaint letters, surveys and so on. At five and six these children had already learned that writing is one way of making their opinions known in the institutional world of the school. At one stage the children opted for a survey of the class and other junior classes in the school. However Vasquez challenged them, by asking what this told them that they didn't already know and what the effects might be. Realizing that the survey may not be the genre for the job, the children continued to consider their options. Vasquez suggested a petition where they could summarize their opinions about the French Cafe and could make suggestions for change and then invite fellow students to sign. The children had never heard of a petition, but quickly saw its 
appropriateness for their problem and began to rehearse how the text might go.

On this occasion we can see the potential for early literacy learning when teachers listen to children's problems within the institutional life of schools. Vasquez was continually alert to children's complaints as a source of learning and action. She describes how children tackled issues such as changing the school LOTE from French to a community language, their difficulties with supply (relieving) teachers and being relocated into a transportable building. Often these problems were initially raised by individual children through written conversations with Vasquez, but at other times they arose in the public forum of the classroom. When this occurred Vasquez encouraged the children to make a note on a classroom wall devoted to this purpose. Vasquez had covered an entire wall with paper in order for children to document their questions and follow-up processes. Here children attached artefacts and reminder notes about academic or social matters over the year, producing what Vasquez describes as an "audit trail" or a "learning wall."

The point to note is that the curriculum was jointly negotiated by the teacher and the children and a visible record of discussions in the classroom was maintained to which teacher and children could and did refer. Children's questions are important reminders of what we as institutional beings have come to take for granted as non- negotiable. Vasquez worked with these questions and concerns and in the process inducted children into powerful literate and language practices for getting things done in the world.

In a similar way but worlds apart, works a grade two/three class and their teacher in suburban Adelaide. ${ }^{9}$ As part of a literacy and social power focus within the school, teachers surveyed the children in their classes about how they wanted the world to be, the kinds of things that made them happy or unhappy, what could be improved in their local area and so on. ${ }^{10}$ The teacher noticed that many of the children mentioned the poor condition of trees and parks in their local area. Following their lead, she copied a street map of the area immediately surrounding the school and, armed with their maps and pencils, the teacher and the children walked the local streets recording the number and condition of visible trees. The children's hunch had been right. There were not many trees and of those many were in poor condition. The school was located in an area of high poverty that had been scheduled for an urban renewal project. These children began to make explicit what it means not to live in a "leafy suburb."

Following their field research, which incorporated key literacy and numeracy skills, the children decided to contact the local council and those people who were in charge of the Urban Renewal Project. This involved composing faxes and letters, making phone calls and designing a survey in order to gauge community opinion.

A detailed analysis of this project is beyond the scope of this paper, but I want to make several observations. Once again the teacher took seriously children's knowledge and analyses of their world. Rather than her original questionnaire being just another artefact for the portfolio, she acted on the common problem identified by many of the children and she demonstrated how to find out more. The children learned to write persuasive and tactful complaint letters in the context of a real issue that already affected them and, when 
the Council promised to improve the number and condition of trees in the area, they learned that their writing could affect some change.

These teachers work with what children bring, but they do not stop there. They show children how to use new and unfamiliar literate practices to make their thinking known and attempt social change. Surely there can be no greater motivator for reading and writing than real material change in one's immediate life. Helping children enjoy the payoffs for literate work is crucial as many children may not have access to demonstrations of these forms of social action in their communities and homes.

\section{Popular Culture}

As we have seen teachers and children can engage meaningfully in serious business with literacy from the start of school. Working with children's knowledge and preoccupations result in powerful and pleasurable learning for teachers and children. A further site of expertise for many children is popular culture-from television, to Nintendo, to videos to movies. Often these forms of knowledge and practices are excluded from school. While they may be powerful determinants of the social life of the classroom, playground, and who visits whom after school, often the popular is excluded from school and seen as inappropriate, violent, commercial, and harmful. ${ }^{11}$

The moral panic associated with popular culture has not surprisingly made teachers wary of its use. And when it has been brought into the world of the school it has been in the name of education or with a corrective intent. ${ }^{12}$ Jennifer O'Brien notes, for example, how in the National English Statement and Profile popular literature is recognized as a valid form of texts for classroom use, but that it is usually paired with the "critical." O'Brien suggests that by implication the inclusion of the popular is provisional and contingent on its being properly critiqued.

One of the most inspiring accounts of teachers using the world of popular culture as a bridge to the official worlds of school literacy is that of Anne Haas Dyson. ${ }^{13}$ Herself a former early childhood teacher, Dyson has documented the ways in which children's knowledge of popular culture can be a powerful resource in appropriating school literate practices if it is allowed and worked on in the classroom.

Focussing on an event she names Author's Chair, Dyson takes us into the social worlds of children writing and acting at school. When in the Author's Chair, the children become script writers and directors for the ir peers who enact their assigned roles. Dyson dramatically narrates how children drawing on their knowledge of screen heroes, such as $\mathrm{X}-\mathrm{Men}$, Ninjas and Power Rangers, write and enact complex scripts about relations of power. Rather than having their knowledge of popular culture excluded as potentially dangerous, their teacher encourages the children to work with, on and against it, but all the while seeing its potential as both powerful and pleasurable.

A number of local educators have been inspired by the work of Anne Dyson and her cooperating teachers and are beginning to explore the wavs in which popular culture mav 
become a resource in the literacy classroom. ${ }^{14}$ Much of this work is in its early stages, but one observation made by teachers is how they have been staggered by just how much children know - about language use, how it works and how to compose-when they allow children to work with the knowledges and practices they acquire from popular culture. As Kavanagh points out, rather than presenting as passive dupes subjected to a media culture, children often prove to be highly sophisticated analysts of the screen and its associated paraphernalia, such as toys, games and so on.

The educators upon whose work I have drawn here have some things in common. They build their curriculum and research around manifest respect for children's funds of knowledge; they include children's existing textual practices as valid classroom repertoires; they take seriously children's analyses of everyday life in and out of school; they attend to and respond to the content of children's spoken and written texts; and they use their knowledge of how language works to assist children with writing, reading and speaking as powerful social practices.

\section{"Coming, Ready or Not!"}

To conclude, I return to the title of this paper. It is deliberately ambiguous and it is to that ambiguity that I now turn. Children arrive at school "more or less" ready for what awaits them. Schools and their teachers are similarly "more or less" ready for the children who inhabit them. Schools are indeed, like most institutions, very strange places. They organize time, space, resources, bodies, talk, social interaction, food and literate practices in which are institutionally specific and alien to the logic of everyday home and community living.

Sometimes teachers discount children's preschool, home and community experiences as limited, non-existent or as chaotic. ${ }^{15}$ Teachers need to learn about how children live in homes and communities - the complexity of networks that support families with minimal economic resources, their sophisticated multilingual and/or multi-modal language use and production, their multiple responsibilities for siblings and elders, the independent negotiation of service encounters, their encyclopedic knowledge of television and popular culture.

Teaching always involves evaluations of what counts as valued performance and knowledge. Designing curriculum is about making some things more important than others, including some cultural practices and excluding others. So it is a time for taking stock and working out what is worth fighting for; what kinds of repertoires of knowledge, skills, forms of pleasure should we make spaces for in early childhood classrooms and as we make those decisions we need to consider the children who most need what schools have to offer. It is my argument that teachers make ready for different children, to respect, appreciate and work with what they know, and to be ready to offer complex and sophisticated literate practices through which children can achieve things in their immediate and future worlds. 


\section{Barbara Comber}

\section{ENDNOTES}

${ }^{1}$ Foucault, cited by Barry Smart, Foucault, Marxism and Critique (Londong: Routledge \& Kegan Paul, 1983), 93.

${ }^{2}$ Pierre Bourdieu, Language and Symbolic Power. Ed. J. B. Thompson (Cambridge, Massachusetts: Harvard University Press, 1991).

Pierre Bourdieu and J. Passeron, J., Reproduction in Education, Society and Culture, second ed. (London: Sage Publications, 1990).

${ }^{3}$ J. B. Thompson, J. B. "Editor's Introduction" in Language and Symbolic Power, 17.

${ }^{4}$ Sue Mahony, L. Badger, and Barbara Comber, A Consumer Guide to Toys (Adelaide, Australia: ERA Publications and Martin International, in press).

${ }^{5}$ See Barbara Comber and A. Simpson, "Reading Cereal Boxes" Broadsheet, Texts: The Heart of the English Curriculum (Adelaide: Department for Education and Children's Services, South Australia, 1995), K. Kavanagh, Texts on Television: School Literacies through Viewing in the First Years of School (Adelaide: Department for Education and Children's Services, South Australia, 1997), Allen Luke, JenniferO'Brien, and Barbara Comber, "Making Community Texts Objects of Study," Journal of Language and Literacy, 17, 2 (1994):139-149, Jennifer O'Brien, "Show Mum You Love Her: Taking a New Look at Junk Mail," Reading, 28,1 (1994):43-46.

${ }^{6}$ A. Collins, M. Wells, and J. Jordan, Texts on Television, Case studies at Ferryden Park Primary School (Adelaide: Department for Education and Children's Services, South Australia, 1997).

${ }^{7}$ Barbara Comber and A. Simpson, "Reading Cereal Boxes" Broadsheet, Texts: The Heart of the English Curriculum (Adelaide: Department for Education and Children's Services, South Australia, 1995)

${ }^{8}$ V. Vasquez, "Negotiating Critical Literacies with Young Children," Negotiating Critical Literacies in Classrooms, eds. B. Comber \& A. Simpson (London: The Falmer Press, in press).

V. Vasquez, "A Step in the Dance of Critical Literacy," Reading, 28,1 (1994): 39-43.

${ }^{9}$ The pilot studv "Socio-Economicallv Disadvantaged Students and the Acauisition of 
School Literacies" was a collaborative venture between the Poverty and Isolation Team in the Curriculum Services Division of the Department of Education and Children's Services (DECS) and the Language and Literacy Research Centre at the University of South Australia (Comber, Badger, Nixon \& Pitt, 1997). The study was conducted in three designated "disadvantaged schools" where the schools had made literacy a high priority and where staff were actively working on changing and improving their practices. Teachers in each school community had reputations for constructing responsive and dynamic literacies and for actively working with their communities. As a result of the pilot study, the university research team is undertaking a three year research project in collaboration with the Commonwealth Literacy Program Team, Equity Standards, in the South Australian Department of Education, Training and Employment (DETE) beginning in 1998. The research is funded by a grant from DETE and the Australian Research Council (ARC) Strategic Partnership with Industry Research Partners (SPIRT) scheme.

${ }^{10}$ B. Comber, L. Badger, H. Nixon, H. and J. Pitt, "Socio-economically Disadvantaged Students and the Acquisition of School Literacies: Pilot study" (University of South Australia, report in two volumes to the Department of Education and Children's Services, South Australia, 1997).

${ }^{11}$ See Valerie Walkerdine, Daddy's Girl: Young Girls and Popular Culture (Cambridge, Massachusetts: Harvard University Press, 1997) for a discussion of the classed nature of professed attitudes to popular culture.

${ }^{12}$ K. Kavanagh, Texts on Television: School Literacies through Viewing in the First Years of School (Adelaide: Department for Education and Children's Services, South Australia, 1997) and Jennifer O'Brien, "The 'Critical' and the 'Popular' in Current English Curriculum Documents," Australian Association for Research in Education Annual National Conference, Brisbane, November 30 - December 4, 1997.

13 Anne Haas Dyson, Social Worlds of Children Learning to Write in an Urban Primary School (New York: Teachers College Press, 1993).

${ }^{14}$ See for example A. Collins, M. Wells, and J. Jordan, Texts on Television, Case Studies at Ferryden Park Primary School (Adelaide: Department for Education and Children's Services, South Australia, 1997) and K. Kavanagh, Texts on Television: School Literacies through Viewing in the First Years of School (Adelaide: Department for Education and Children's Services, South Australia, 1997). 15

${ }^{15}$ See Barbara Comber, "The Problem of 'Background' in Researching the Student Subject," The Australian Educational Researcher 25,3: 1-21, 1998, and P. Freebody and A. Welch, "Individualization and Domestication in Current Literacy Debates in Australia", Knowledge and Power: International Perspectives on Literacy as Policy and Practice, eds. P. Freebody and A. Welch (London: The Falmer Press, 1993). 